\title{
Sovereign credit rating determinants: a comparison before and after the European debt crisis
}

\author{
Peter Reusens ${ }^{\mathrm{a}}$, Christophe Croux ${ }^{\mathrm{a}, *}$ \\ ${ }^{a}$ Faculty of Economics and Business, KU Leuven, Belgium.
}

\begin{abstract}
This paper compares the importance of different sovereign credit rating determinants over time, using a sample of 90 countries for the years 2002-2015. Applying the composite marginal likelihood approach, we estimate a multi-year ordered probit model for each of the three major credit rating agencies. After the start of the European debt crisis in 2009, the importance of the financial balance, the economic development and the external debt increased substantially and the effect of eurozone membership switched from positive to negative. In addition, GDP growth gained a lot of importance for highly indebted sovereigns and government debt became much more important for countries with a low GDP growth rate. These findings provide empirical evidence that the credit rating agencies changed their sovereign credit rating assessment after the start of the European debt crisis.

Keywords: Composite marginal likelihood, Credit rating agencies, European debt crisis, Multi-year ordered probit model, Sovereign credit rating determinants
\end{abstract}

JEL: C33, C35, F34, G24, H63

\section{Introduction}

A sovereign credit rating is a measure of the creditworthiness of a sovereign government assigned by a credit rating agency (CRA). Each sovereign credit rating is determined by a rating committee, which assesses the different factors that drive the sovereign's creditworthiness. Rather than computing a fixed weighted average of these factors, CRAs can vary the relative importance of the various factors over time, in response to changing macroeconomic circumstances (Kiff et al., 2010). For instance, Fitch (2014) states they attach more importance to the sovereign public finance ratios and financing

${ }^{*}$ Corresponding author: Faculty of Economics and Business, KU Leuven, Naamsestraat 69 B-3000 Leuven Belgium, Tel: +32 16326958 .

Email addresses: peter.reusens@kuleuven.be (Peter Reusens), christophe.croux@kuleuven. be (Christophe Croux) 
flexibility during crisis periods and Gaillard (2012) argues that, before the outbreak of the European debt crisis, CRAs attached too much value to both the advanced economy status and eurozone membership of Greece. Even though the CRAs regularly publish reports in which they identify the different ingredients of the sovereign credit rating, further judgmental adjustments are made by the rating committee. ${ }^{1}$ Therefore, the actual degree of importance of the different variables and their change over time is not known. In this paper, we quantify, for the three major rating agencies Standard and Poor's (S\&P), Moody's and Fitch, how the importance of different sovereign credit rating determinants changed after the start of the European debt crisis.

Starting with Cantor and Packer (1996), an empirical literature has emerged that analyzes the importance of the determinants of sovereign credit ratings using historical data. In their seminal paper, Cantor and Packer (1996) report that their single-year linear regression model with eight macroeconomic variables could explain more than $90 \%$ of the variability of the sovereign credit ratings for 1995. In particular, they find a statistically significant effect of the variables GDP per capita, GDP growth, inflation, external debt, the economic development and default history. Subsequent research has confirmed the importance of these variables in explaining the sovereign credit rating (Afonso et al., 2011; Gaillard, 2012; Gartner et al., 2011).

Only a few papers have compared the importance of the different credit rating determinants over time. These papers predominantly analyze the change after the 1997-1998 Asian crisis and mostly use linear regression models. Monfort and Mulder (2000) compare estimated coefficients of their panel linear regression model between subperiods 1994-1995, 1996-1997 and 1997-1998. They find stable coefficients across subperiods, with the exception of the export growth rate. Bissoondoyal-Bheenick (2005) estimate single-year ordered probit regression models for the years 1995 to 1999 and finds that mostly the same variables are statistically significant over the different years. Finally, Afonso et al. (2007), estimating a panel linear regression model separately for the period 1996-2000 and 2001-

\footnotetext{
${ }^{1}$ Standard and Poor's scores five key factors of a sovereign's degree of creditworthiness on a six point scale. While the calibration of both the scoring procedure of each factor and the procedure of combining the scores into a single credit rating has been more objectively documented as from 2011, qualitative judgment still remains important in this rating process (S\&P, 2014b). Also Moody's (2015b) uses a scorecard which maps different indicators to four key factors, which are then combined to an initial sovereign credit rating. Although Moody's provides indicative weights of the different determinants of each of these factors, they emphasize that the actual weights can substantially deviate because of supplementary adjustments based on qualitative judgment. Finally, the rating process of Fitch (2014) starts from the rating prediction of a linear regression model in which 19 variables are regressed on historical Fitch sovereign credit ratings and which is yearly re-estimated for a sample starting in 2000. Also here, the rating committee makes substantial changes to this initial rating prediction.
} 
2006, conclude that most estimated coefficients are similar across subperiods, which they interpret as evidence for a rather stable credit rating process over time.

This paper builds on above literature that compares the importance of the different factors of sovereign credit ratings over time. Using a sample of 90 countries for the period 2002-2015, we investigate if and how the importance of the sovereign credit rating determinants changed after the start of the European debt crisis in 2009. This analysis is performed for each of the three major rating agencies Standard and Poor's (S\&P), Moody's and Fitch and the focus is predominantly on common patterns over time. Estimating a multi-year ordered probit model using a composite marginal likelihood estimation approach, we are the first to take into account both the ordinal nature of the sovereign credit rating and the serial correlation of the error terms. We compare the importance of the different credit rating determinants over time, whereas the existing literature that uses an ordered probit model, has only analyzed the statistical significance and the sign of the estimated coefficients. A difficulty is that the coefficients of different ordered probit models are not directly comparable over time, because their scaling depends on the unobserved degree of residual variation (Allison, 1999).

While previous literature has predominantly focused on the impact of the Asian crisis on the different credit rating determinants, we analyze the impact of the European debt crisis. For each of the three major credit rating agencies, we find that, after the start of the European debt crisis in 2009, the importance of the financial balance, the economic development and the external debt increased substantially and that the effect of eurozone membership switched from positive to negative. In addition, GDP growth gained a lot of importance, especially for highly indebted sovereigns, and government debt became much more important, especially for countries with a low GDP growth rate. These findings provide empirical evidence that the CRAs changed their sovereign credit rating assessment after the start of the European debt crisis.

Our paper is organized as follows. Section 2 discusses the data and Section 3 presents the multiyear ordered probit model. Then, Section 4 discusses the results and Section 5 concludes our findings.

\section{Data}

We use data for the $T=14$ years between 2002 and 2015. For the three major rating agencies S\&P, Moody's and Fitch, we have a balanced panel dataset for respectively 85, 90 and 69 advanced and emerging countries, listed in Table A.3 of Appendix A.

We model end-of-year sovereign credit ratings, which are obtained from S\&P, Moody's and Fitch. The different rating categories are shown in Table A.1 of Appendix A. Summary statistics for the frequency of rating changes within a given year, presented in Table 1, show that this frequency of 
within-year rating changes is small: it is zero or one for more than $90 \%$ of the sample observations and its average equals $0.35,0.26$ and 0.28 per year for S\&P, Moody's and Fitch, respectively.

Table 1: Summary statistics for the frequency of within-year rating changes.

\begin{tabular}{lrrrrrrrr}
\hline & Min. & 10th Perc. & 1st Qu. & Median & Mean & 3rd Qu. & 90th Perc. & Max. \\
\hline S\&P & 0 & 0 & 0 & 0 & 0.35 & 1 & 1 & 5 \\
Moody's & 0 & 0 & 0 & 0 & 0.26 & 0 & 1 & 4 \\
Fitch & 0 & 0 & 0 & 0 & 0.28 & 0 & 1 & 4
\end{tabular}

We use ten rating determinants in our model. We include GDP per capita, government debt, GDP growth, inflation, financial balance, external debt, current account and dummy variables for economic development and default history, which have been previously shown to be important drivers for the creditworthiness (Afonso et al., 2011; Cantor and Packer, 1996; Elkhoury, 2007; Gaillard, 2012). In addition, we include the dummy variable for eurozone membership, which importance is expected to have changed after the European debt crisis. The data definitions, data sources and expected sign of the effect of the determinants on the credit rating are shown in Table 2 and summary statistics are presented in Table 3 .

Table 2: Definitions of the explanatory variables, the source of the data and the expected sign of the impact of the variables on the credit rating.

\begin{tabular}{lll}
\hline Variable name & Definition & Source \\
\hline GDP per capita & GDP per capita, PPP (international dollars) & IMF, WEO Oct2015 \\
Government debt & General government gross debt (\% of GDP) & IMF, WEO Oct 2015 \\
GDP growth & Real GDP growth (annual \%) & IMF, WEO Oct 2015 \\
Eurozone membership & Member country of the European Monetary Union & ECB \\
Financial Balance & Financial balance (\% of GDP) & Moody's $(2015 \mathrm{a})$ \\
Economic development & Member country of the OECD & OECD \\
External debt & External debt (\% of GDP) (developing countries) & Moody's $(2015 \mathrm{a})$ \\
Current account & Current account balance (\% of GDP) & IMF, WEO Oct 2015 \\
Inflation & Inflation, end of period consumer prices (annual \%) & IMF, WEO Oct 2015 \\
Default history & Sovereign default since 1975 & Beers and Nadeau $(2015)$ \\
\hline
\end{tabular}

For each determinant, the expected sign of its effect on the credit rating is motivated as follows:

- GDP per capita: Countries with a higher GDP per capita are expected to have a higher sovereign credit rating, conditioning on the other variables in the model. These countries have a higher potential tax base and they often have a sound political and institutional stability.

- Government debt: Countries with a higher level of government debt relative to GDP are 
Table 3: Summary statistics for each variable, computed over all observations that have an $\mathrm{S} \& \mathrm{P}$ rating for the years 2002 to 2015 .

\begin{tabular}{lrrrrrr}
\hline & Min. & 1st Qu. & Median & Mean & 3rd Qu. & Max. \\
\hline GDP per capita & 1353.00 & 10300.00 & 20110.00 & 24940.00 & 35160.00 & 149600.00 \\
Government debt & 0.06 & 28.50 & 43.46 & 52.11 & 67.63 & 246.20 \\
GDP growth & -15.14 & 1.55 & 3.30 & 3.44 & 5.47 & 26.17 \\
Eurozone membership & 0.00 & 0.00 & 0.00 & 0.17 & 0.00 & 1.00 \\
Financial balance & -32.30 & -4.38 & -2.30 & -1.86 & -0.10 & 40.80 \\
Economic development & 0.00 & 0.00 & 0.00 & 0.36 & 1.00 & 1.00 \\
External debt & 0.00 & 0.00 & 25.80 & 33.38 & 45.95 & 965.00 \\
Current account & -53.56 & -4.55 & -0.83 & 0.04 & 3.67 & 45.22 \\
Inflation & -4.90 & 1.61 & 3.08 & 4.64 & 5.86 & 190.00 \\
Default history & 0.00 & 0.00 & 1.00 & 0.52 & 1.00 & 1.00 \\
\hline
\end{tabular}

expected to have a lower sovereign credit rating.

- GDP growth: Countries with a higher GDP growth rate are expected to have a higher sovereign credit rating, because a higher GDP growth rate is indicative for a higher future GDP growth rate, which increases the future potential tax base and reduces the future government debt to GDP ratio.

- Eurozone membership: Membership to the eurozone monetary union ${ }^{2}$ has an ambiguous impact on the sovereign credit rating of its member states. On the one hand, enforceable rules for fiscal discipline, such as the Stability and Growth Pact, increase the fiscal credibility of its member states (Afonso et al., 2011; Gartner et al., 2011). Eurozone membership also provides several economic advantages for member states, such as decreased transaction costs and reduced price uncertainty, which lead to increased trade and economic activity. Another advantage is that the euro is an actively traded currency, such that the member country can more easily issue debt in domestic currency (S\&P, 2014a). On the other hand, member countries in a monetary union are prone to a self-fulfilling liquidity crisis. As these member countries cannot force the central bank to alleviate a liquidity crisis by buying their government debt, they can face higher interest rates during a liquidity crisis. This high interest rate, together with the fact that economic growth cannot be boosted through currency depreciation, implies that a liquidity crisis can easily spillover into a solvency crisis (De Grauwe and Ji, 2013).

\footnotetext{
${ }^{2}$ Note that we do not investigate the effect of membership to other currency unions, since too few of those member states have a sovereign credit rating.
} 
- Financial balance: A positive financial balance relative to GDP signals that the government is able and willing to increase taxes or reduce expenses in order to service its debt.

- Economic development: Countries that are classified as economically developed, are expected to have a higher credit rating. They are perceived to have attained a certain threshold of economic development for which default is very unlikely. In addition, these countries are often strongly integrated with the world economy, such that a default is less likely, as foreign creditors can more easily disrupt trade or seize assets abroad in case of default (Cantor and Packer, 1996).

- External debt: Countries with a high external debt relative to GDP have a high total debt burden, such that additional taxes or reduced government expenses are needed in order to reduce the government's debt or to support over-indebted domestic borrowers (Afonso et al., 2011). Given that data on the external debt is missing for many industrialized countries, we only analyze its effect for developing countries (as defined in Moody's, 2015a), by setting the external debt to zero for the industrialized countries, in line with Hill et al. (2010) and Afonso et al. (2011).

- Current account: The current account balance of a country has an unclear impact on its sovereign credit rating. While a current account surplus is expected to positively impact the credit rating, the effect of a current account deficit on the credit rating depends on the productivity of the investment it finances.

- Inflation: A high inflation rate may be a symptom of macroeconomic problems and can lead to dissatisfied inhabitants and corresponding political instabilities (Afonso et al., 2011; Bissoondoyal-Bheenick et al., 2006). This negative effect is partly offset because high inflation also lowers the real stock of outstanding government domestic currency debt and because a rate of inflation that is too low may lead to a deflationary spiral.

- Default history: Sovereigns that have previously defaulted on their debt, are seen as being less willing to repay their debt.

Finally, we also add the interaction term ${ }^{3}$ between GDP growth and government debt to the model, because GDP growth matters more for the sovereign's creditworthiness, if the level of government

\footnotetext{
${ }^{3}$ The interaction term is computed as the product of the centered GDP growth rate and the centered government debt ratio, in which the overall mean is used to center the variables (i.e. $3.348 \%$ for GDP growth rate and $52.455 \%$ for government debt).
} 
debt is high. In particular, an increase in the GDP growth rate reduces the future government debt ratio, and hence increases the sovereign's creditworthiness, by an amount proportional to the debt ratio. ${ }^{4}$ Therefore, we expect this interaction effect to be positive.

\section{Methodology}

In early research on the determinants of sovereign credit ratings, a linear regression model was used in which the dependent variable credit rating was transformed to a linear scale. We believe this linear model to be inappropriate for two reasons. First, the linear regression model assumes that the absolute distances in the underlying degree of creditworthiness between subsequent credit rating categories are equally spaced. This assumption is not realistic for credit ratings as they are only ordinal measures for the sovereign's degree of creditworthiness, see e.g. Afonso et al. (2011), Bissoondoyal-Bheenick (2005) and Mora (2006). Second, McKelvey and Zavoina (1975) have shown that, even if the degree of creditworthiness were equally spaced between rating categories, applying linear regression to ordinal data would still result in a bias in the estimated coefficients. Christensen (2015) states that this bias of the linear model is small only if there are many response categories and if the responses do not pile up in the end categories. Given that $17 \%, 19 \%$ and $21 \%$ percent of ratings has the highest rating category for S\&P, Moody's and Fitch respectively, the bias is expected to be considerable.

The ordered regression model is not subject to the above discussed disadvantages of the linear regression model and it is increasingly used for modeling sovereign credit ratings. BissoondoyalBheenick (2005) and Gaillard (2012) use a single-year ordered regression model for sovereign credit ratings. Also, Hill et al. (2010) and $\mathrm{Hu}$ et al. (2002) estimate an ordered regression model, pooling data from multiple years. These single-year and pooled ordered probit models do not exploit the panel data structure of sovereign credit ratings, collected over a span of fourteen years. Subsequently, Afonso et al. (2009) and Mora (2006) estimate a panel ordered probit model, respectively using random and fixed effects. However, as these models assume that both the regression coefficients and threshold parameters are constant over time, they do not allow for a comparison of the coefficients over time.

We use a multi-year ordered probit regression model, which allows for time variation in the regression coefficients and explicitly models the correlation between the error terms over the years.

\footnotetext{
${ }^{4}$ Indeed, keeping the total real amount of government debt constant, we would have that next year's government debt ratio equals $\frac{d}{1+g} \approx d-d g$, with $g$ the real GDP growth rate and $d$ the present debt ratio.
} 
Our model is similar to the cross-sectional multivariate ordered response model used by Bhat et al. (2010) and Ferdous et al. (2010) to assess the determinants of the level of non-work activities.

\subsection{The multi-year ordered probit regression model}

Consider the latent regression equation

$$
Y_{i t}^{*}=\beta_{t}^{\prime} x_{i t}+\nu_{i t}
$$

for $i$ in $1, \ldots, N$ and $t$ in $1, \ldots, T$, where $N$ is the number of countries and $T$ is the number of time periods, $Y_{i t}^{*}$ is an unobserved latent variable measuring the degree of creditworthiness of sovereign $i$ at time $t, x_{i t}$ is a vector of $p$ explanatory variables of sovereign $i$ at time $t, \beta_{t}$ is a vector of unknown parameters at time $t$, and $\left(\nu_{i 1}, \ldots, \nu_{i T}\right)$ are jointly standard normally distributed error terms with correlation matrix $\Sigma$ which are independent across countries and independent from the covariates. ${ }^{5}$ In order to reduce the number of free parameters in the correlation matrix $\Sigma$, we hypothesize, in line with Varin and Czado (2010), that the error term of each sovereign $i$ follows an autoregressive process of order one with common autoregressive parameter $\rho$, so that the element of $\Sigma$ at row $s$ and column $t$, is given by $\Sigma_{s t}=\rho^{|t-s|}$.

The threshold specification is given by

$$
Y_{i t}= \begin{cases}1 & \text { if }-\infty<Y_{i t}^{*}<\tau_{t}^{1} \\ l & \text { if } \tau_{t}^{l-1} \leq Y_{i t}^{*}<\tau_{t}^{l} \text { for } l=2, \ldots, C_{t}-1 \\ C_{t} & \text { if } \tau_{t}^{C_{t}-1} \leq Y_{i t}^{*}<\infty\end{cases}
$$

for $i$ in $1, \ldots, N$ and $t$ in $1, \ldots, T$, where $Y_{i t}$ is the observed credit rating, $\tau_{t}^{l}$ is a threshold parameter and $C_{t}$ represents the number of observed rating categories in the sample for time $t .{ }^{6}$ For notation purpose, we label $\tau_{t}^{0}=-\infty$ and $\tau_{t}^{C_{t}}=\infty$. In sum, the parameters of the model are the $p T$ coefficients $\beta_{t}$, the $\sum_{t=1}^{T}\left(C_{t}-1\right)$ threshold parameters $\tau_{t}^{l}$ and the correlation parameter $\rho$, and we collect them in the vector $\theta$.

\footnotetext{
${ }^{5}$ The scaling of the variances of the error terms $\nu_{i t}$ to 1 and the absence of intercept coefficients are necessary to identify the model parameters.

${ }^{6}$ If a certain rating category is not observed in the sample, there is no information in the data to identify its corresponding threshold parameter. Although each CRA has 21 rating categories, the number of observed different rating categories $C_{t}$ varies over the years between 16 and 19 for S\&P, between 17 to 19 for Moody's and between 15 to 18 for Fitch.
} 


\subsection{The likelihood function}

The likelihood function is given by

$$
L(\theta)=\prod_{i=1}^{N} L_{i}(\theta)
$$

where $L_{i}(\theta)$ is the likelihood for sovereign $i$, given by

$$
\begin{gathered}
L_{i}(\theta)=P\left(Y_{i 1}=y_{i 1}, \ldots, Y_{i T}=y_{i T}\right) \\
=\int_{\nu_{i 1}=\tau_{1}^{y_{11}-1}-\beta_{1}^{\prime} x_{i 1}}^{\tau_{1}^{y_{i 1}}-\beta_{1}^{\prime} x_{i 1}} \ldots \int_{\nu_{i T}=\tau_{T}^{y_{i}-1}-\beta_{T}^{\prime} x_{i T}}^{\tau_{T}^{y_{i T}}-\beta_{T}^{\prime} x_{i T}} \phi\left(\nu_{i 1}, \ldots, \nu_{i T} ; \Sigma\right) d \nu_{i 1} \ldots d \nu_{i T},
\end{gathered}
$$

where $y_{i t}$ is the observed category number of variable $Y_{i t}$ and $\phi\left(\nu_{i 1}, \ldots, \nu_{i T} ; \Sigma\right)$ is the density of the multivariate normal distribution with zero mean and correlation matrix $\Sigma$.

Since the $T$-dimensional integral in (4) cannot be easily computed for dimensions larger than two, a classical maximum likelihood estimation is not feasible. One could approximate the $T$-dimensional integral in (4) using simulation techniques, but the corresponding simulated maximum likelihood estimator should not be used for high dimensional multivariate ordered response settings, due to computational convergence issues (Bhat et al., 2010).

\subsection{The composite likelihood estimator}

The composite likelihood estimator $\hat{\theta}$ (Bhat et al., 2010) maximizes the composite likelihood function

$$
L^{C}(\theta)=\prod_{i=1}^{N} L_{i}^{C}(\theta)
$$

with $L_{i}^{C}(\theta)$ the pairwise marginal likelihood function for sovereign $i$

$$
L_{i}^{C}(\theta)=\prod_{s=1}^{T-1} \prod_{t=s+1}^{T} P\left(Y_{i s}=y_{i s}, Y_{i t}=y_{i t}\right),
$$

where $y_{i s}$ and $y_{i t}$ denote the observed category of variables $Y_{i s}$ and $Y_{i t}$, and $P\left(Y_{i s}=y_{i s}, Y_{i t}=y_{i t}\right)$ is the probability of their joint occurrence. It is a consistent and asymptotically normally distributed estimator with covariance matrix $\operatorname{Cov}(\hat{\theta})$. Complete expressions for the composite likelihood function, the estimates of $\operatorname{Cov}(\hat{\theta})$ and implementation details of the composite likelihood estimator are given in Appendix B. 


\subsection{Comparing coefficients over time in the multi-year ordered probit model}

The estimated coefficient $\hat{\beta}_{t}^{v}$ represents the estimated effect for time $t$ of a one unit increase in the variable $v$ on the underlying degree of creditworthiness $Y_{i t}^{*}$, keeping the other variables constant. However, a direct comparison over time of these estimated coefficients is not meaningful, because the unit of measurement of the unobserved underlying degree of creditworthiness $Y_{i t}^{*}$ differs over time (Allison, 1999). This change in unit of measurement arises because the variances of the error terms in the ordered regression model are scaled to one.

As a solution, we apply the approach of Hoetker (2004) and Hoetker (2007), originally proposed for comparing coefficients across binary choice models. This entails a scaling of the coefficients across time. Let GDP per capita be the first variable. We will analyze the ratio $R_{t}^{v}$, which we call the importance of the variable,

$$
R_{t}^{v}=\frac{\beta_{t}^{v}}{\beta_{t}^{G D P}} \text { for } v \text { in } 2, \ldots, p \text { and } t \text { in } 1, \ldots, T,
$$

where $\beta_{t}^{G D P}$ is the coefficient of the variable GDP per capita. The interpretation of this ratio is that, ceteris paribus, a one unit increase in the variable of interest is expected to have the same effect on the degree of creditworthiness as an increase in GDP per capita by the amount equal to the value of this ratio. This ratio can also been interpreted in terms of the 'compensating variation' used in Boes and Winkelmann (2006), Train (1998) and Train (2003): it represents the required increase in GDP per capita necessary to offset a one unit decrease of the variable $v$, such that the sovereign's degree of creditworthiness remains the same.

The importance $R_{t}^{v}$ is estimated by the sample counterpart of (7), where the coefficients $\beta_{t}^{v}$ and $\beta_{t}^{G D P}$ are replaced by their composite likelihood estimate of Section 3.3. The estimated covariance matrix of $\hat{R}_{t}^{v}$ is obtained using the Delta method and the estimated covariance matrix, given in Appendix B.2.

\section{Results}

\subsection{Estimated importance of the credit rating determinants}

For the different determinants $v$ and the different time periods $t$, Figures 1, 2 and 3 show the estimated importance $\hat{R}_{t}^{v}$, as defined in Section 3.4, for S\&P, Moody's and Fitch, respectively. ${ }^{7}$

\footnotetext{
${ }^{7}$ Note that for each variable $v$ and time period $t$, the estimated importance $\hat{R}_{t}^{v}$ and the estimated coefficient $\hat{\beta}_{t}^{v}$ have the same sign and a similar significance pattern, because the estimated ordered probit coefficient of GDP per capita $\hat{\beta}_{t}^{G D P}$ is positive and significant for each year (the estimated ordered probit coefficients are available upon request).
} 

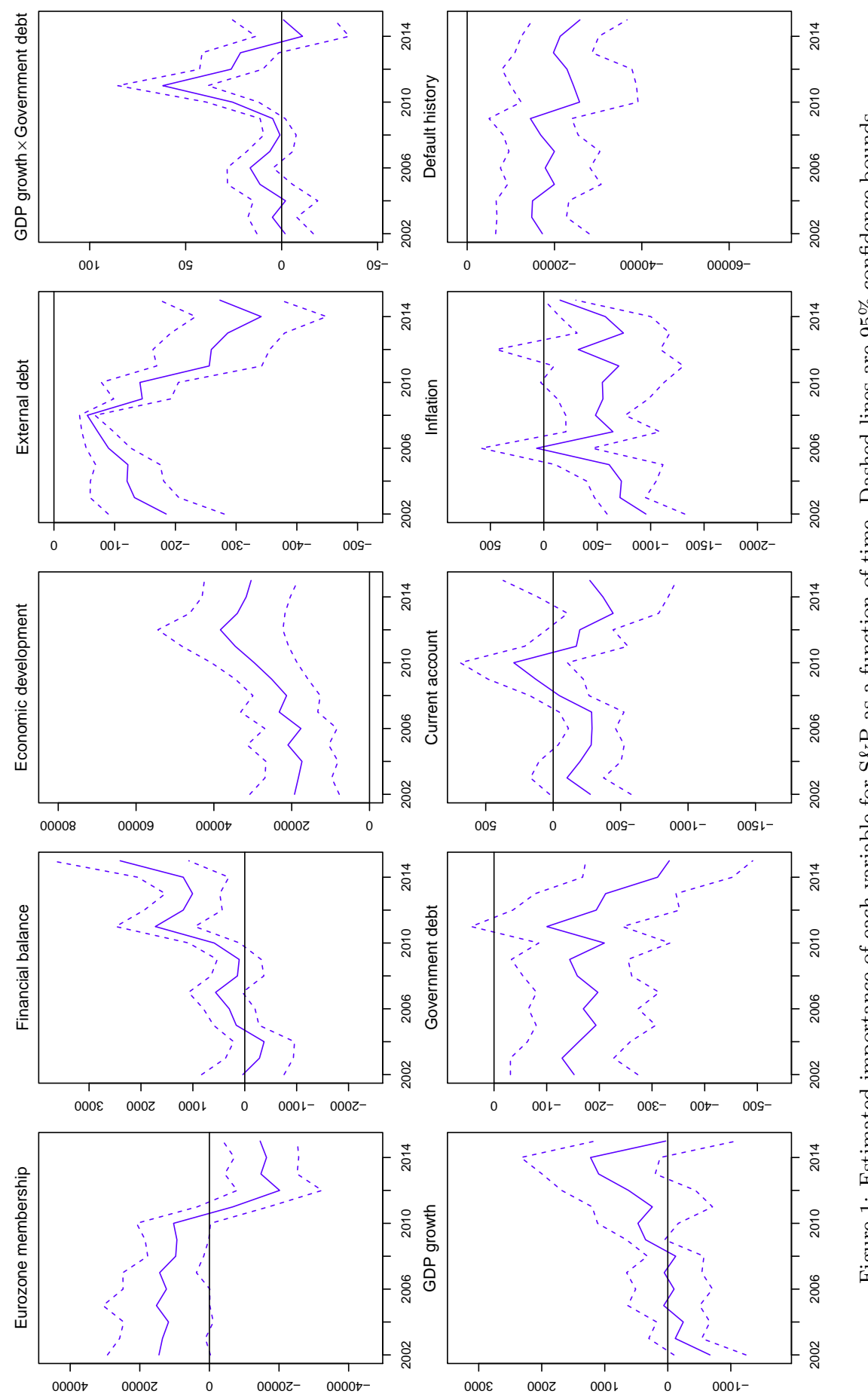

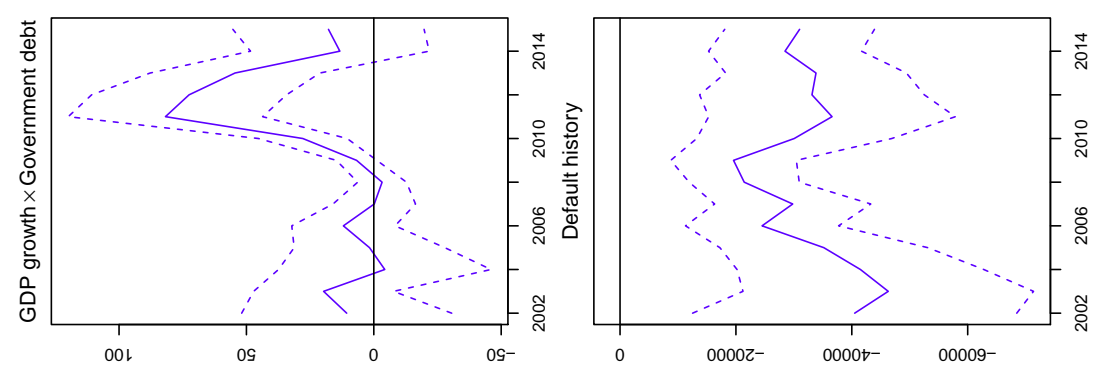

$\dot{0}$
0
0
0
0
0
0
0
0
0
0
0
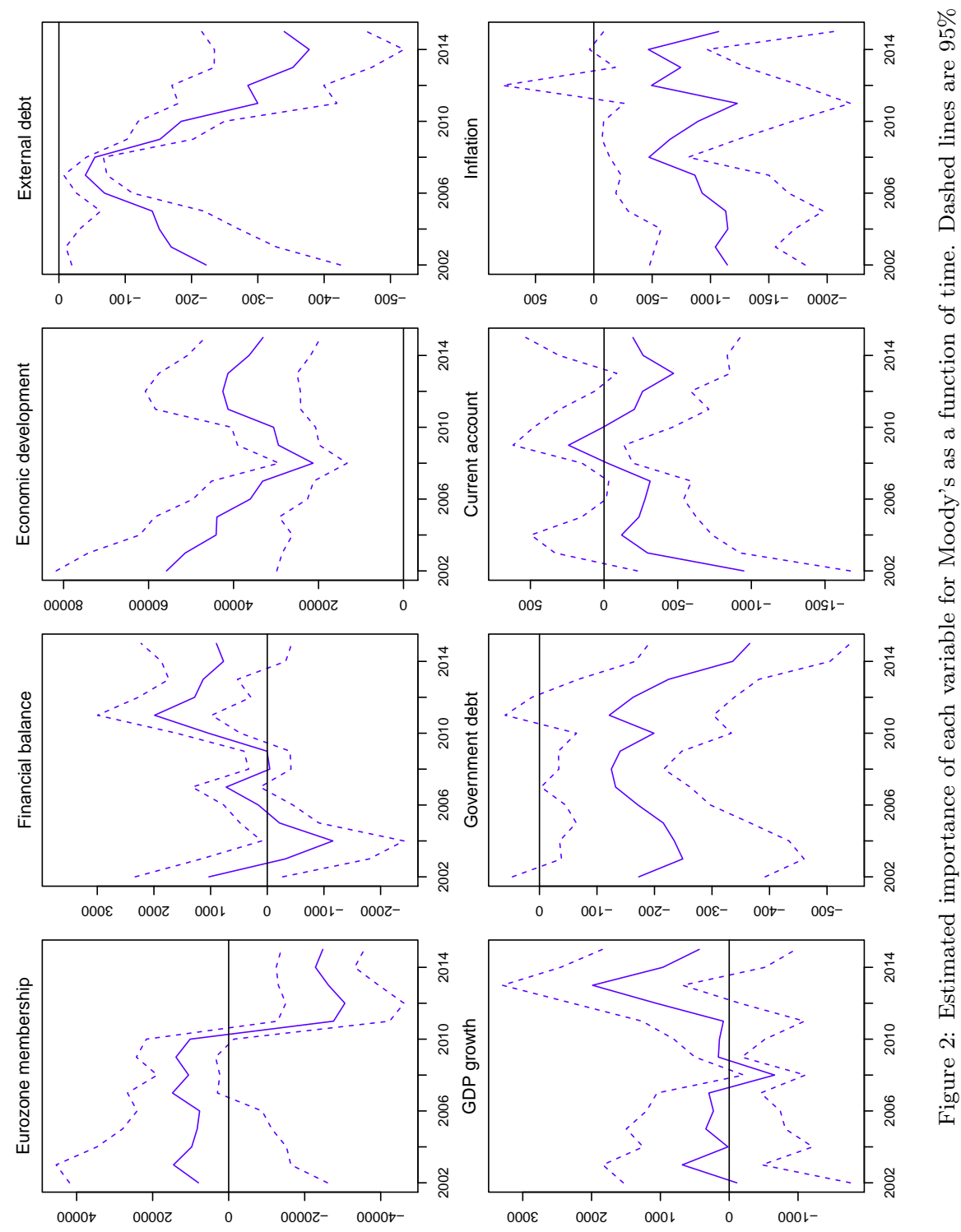

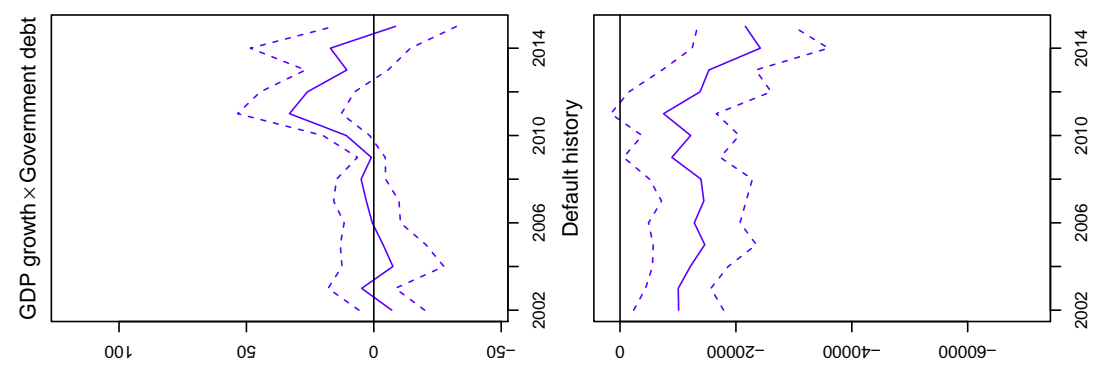

$\dot{8}$
0
0
0
0
0
0
0
0
0
0
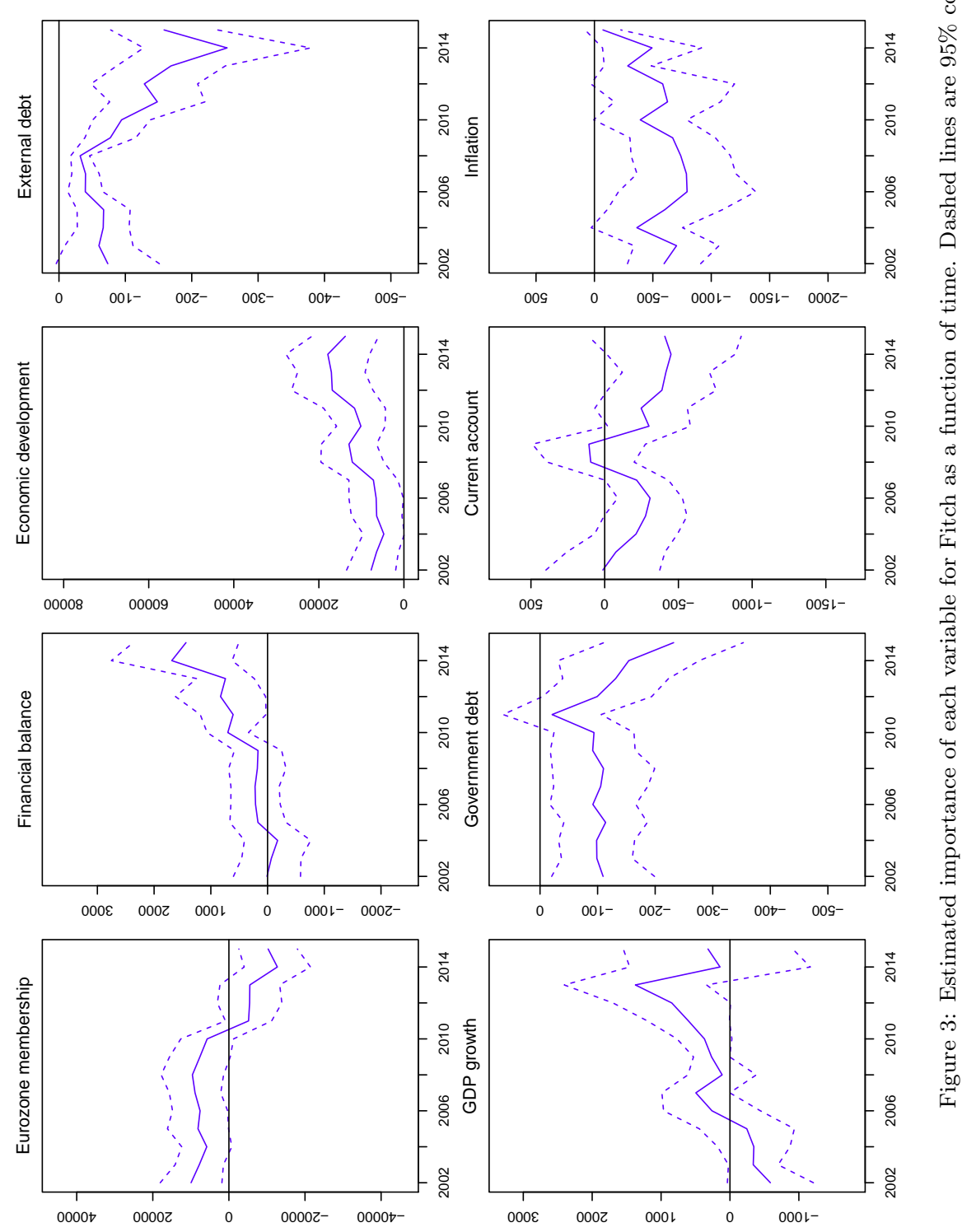
As elaborated in Section 3.4, this ratio quantifies the importance of each determinant and it represents the required increase in GDP per capita necessary to offset a one unit decrease of the determinant such that the sovereign's degree of creditworthiness remains the same. The figures also show the pointwise $95 \%$ confidence bounds. We detect important changes in the importance of the different variables after the start of the European debt crisis in 2009. Averages for the estimated importance $\hat{R}_{t}^{v}$ over the period 2002-2008 and over the period 2009-2015 are shown in Table 4.

Table 4: For each variable and each CRA, the table shows the average estimated importance $\hat{R}_{t}^{v}$ for the period 20022008 (left panel) and for the period 2009-2015 (middle panel), as well as the P-values of the Wald hypothesis test that the average importance is the same for both periods (right panel).

\begin{tabular}{rccc|ccc|ccc} 
& \multicolumn{3}{c|}{ Average $\hat{\boldsymbol{R}}_{\mathbf{2 0 0 2}-\mathbf{2 0 0 8}}^{\boldsymbol{v}}$} & \multicolumn{3}{c|}{ Average $\hat{\boldsymbol{R}}_{\mathbf{2 0 0 9 - 2 0 1 5}}^{\boldsymbol{v}}$} & \multicolumn{3}{c}{$\boldsymbol{H}_{\mathbf{0}}$ : No break in 2009 } \\
\hline & $\mathrm{S} \& \mathrm{P}$ & Moody's & Fitch & S\&P & Moody's & Fitch & S\&P & Moody's & Fitch \\
\hline Eurozone membership & 13037 & 10489 & 8249 & -7581 & -15435 & -3688 & $\mathbf{0 . 0 0 0}$ & $\mathbf{0 . 0 0 2}$ & $\mathbf{0 . 0 0 0}$ \\
Financial balance & 78 & 25 & 78 & 1171 & 1016 & 882 & $\mathbf{0 . 0 0 1}$ & $\mathbf{0 . 0 3 1}$ & $\mathbf{0 . 0 0 4}$ \\
Economic development & 19720 & 40808 & 7303 & 31961 & 36363 & 14321 & $\mathbf{0 . 0 0 6}$ & 0.549 & $\mathbf{0 . 0 0 4}$ \\
External debt & -111 & -121 & -54 & -243 & -285 & -147 & $\mathbf{0 . 0 0 0}$ & $\mathbf{0 . 0 0 1}$ & $\mathbf{0 . 0 0 0}$ \\
GDP growth $\times$ Gov. debt & 5 & 5 & -1 & 18 & 39 & 13 & 0.072 & $\mathbf{0 . 0 0 8}$ & 0.054 \\
GDP growth & -163 & 114 & -92 & 578 & 690 & 560 & $\mathbf{0 . 0 3 0}$ & 0.241 & $\mathbf{0 . 0 3 7}$ \\
Government debt & -166 & -186 & -104 & -215 & -221 & -118 & 0.206 & 0.558 & 0.648 \\
Current account & -211 & -316 & -140 & -148 & -165 & -300 & 0.655 & 0.488 & 0.274 \\
Inflation & -581 & -962 & -655 & -514 & -793 & -446 & 0.706 & 0.624 & 0.179 \\
Default history & -17378 & -34168 & -12593 & -22045 & -30378 & -14803 & 0.219 & 0.597 & 0.475 \\
\hline
\end{tabular}

The effect of eurozone membership, financial balance, economic development and external debt on the credit rating changed substantially after 2009. (i) While the estimated importance of eurozone membership was statistically significant and positive before 2009, on average about 10000, it substantially decreased after 2009 and became significant and negative, on average about -8000 , -15000 and -4000 for S\&P, Moody's and Fitch, respectively. (ii) While before 2009, the importance of the financial balance to GDP ratio was insignificant, it became significant and positive afterwards. After 2009, a one percentage point increase in the financial balance is expected to have the same effect on the credit rating as an increase in GDP per capita by about $1000 \$$, on average. (iii) The estimated importance of economic development increased after 2009 for S\&P and Fitch. For Moody's, however, the picture is less clear. (iv) The importance of external debt is significant and negative for all years and it decreased substantially from about -100 before 2009 to about -250 for the period after 2009 .

Also the effect of government debt and GDP growth rate on the credit rating changed substantially after 2009. The graphs of the importance of GDP growth and government debt correspond to a country with an average value for these variables. (i) The interaction term between GDP growth 
rate and government debt is significant and positive between 2009 and 2013. (ii) For a country with an average debt ratio, the importance of GDP growth rate was insignificant for the years before 2009 and positive and often significant for the years after 2009. For a highly indebted sovereign with a government debt ratio of $100 \%$ (i.e. the 90 th percentile of the government debt ratio in our sample), the total effect of a one percentage point increase of GDP growth after 2009 is equivalent to an increase in GDP per capita of about $1400 \$, 2600 \$$ and $1200 \$$ for S\&P, Moody's and Fitch, respectively. In contrast, for a lowly indebted sovereign with a government debt ratio of $20 \%$ (i.e. the 10th percentile of the government debt ratio), the total effect of a one percentage point increase of GDP growth has remained close to zero. (iii) For a country with an average GDP growth rate, the importance of government debt has the expected negative sign and is significant for most years; it increased in magnitude by about $20 \%$ after 2009. For countries with a GDP growth rate of $-1 \%$ (the 10th percentile), the importance of government debt increased substantially in magnitude after 2009 to $-300,-400,-180$ for S\&P, Moody's and Fitch, respectively, whereas the importance of government debt remained equal to about -150 for countries with a GDP growth rate of $6 \%$ (the 90th percentile).

The estimated importance of the other variables remained relatively constant over the sample period. (i) The current account balance is insignificant for nearly all years. (ii) The estimated effect of a one percentage point decrease in inflation is significant for most years and corresponds to an increase in GDP per capita of about $550 \$, 880 \$$ and $550 \$$ for S\&P, Moody's and Fitch, respectively. (iii) The estimated importance of the default history is negative and significant. In particular, the impact of having defaulted in the last decades is equivalent to an increase in GDP per capita by about $-19000 \$,-32000 \$$ and $-14000 \$$ for S\&P, Moody's and Fitch, respectively.

Finally, the estimated autoregressive parameter $\rho$ of the error term $\nu_{i t}$ is large: $0.965,0.953$ and 0.961 for S\&P, Moody's and Fitch, respectively. Therefore, a sovereign which received a higher (lower) rating than expected based on the rating determinants for a given year, is also very likely to have a higher (lower) rating than expected for the following years. This high serial correlation is indicative for persistent omitted variables and strengthens the benefit of using a multi-year ordered probit model because the efficiency gain over the estimation of a single-year ordered probit model is substantial when the correlation of the error terms is large.

\subsection{Test for a break}

We perform two hypothesis tests. First, we test for each variable $v$, the hypothesis that its importance is constant across all years

$$
H_{0}: R_{1}^{v}=\ldots=R_{T}^{v}
$$


Table 5 shows the P-values of the Wald test for this null hypothesis. For most variables and CRAs, we reject this null hypothesis at the $5 \%$ significance level, which motivates the use of a model that allows for time variation in the ordered probit coefficients, rather than a fixed coefficients panel model.

Table 5: P-values of the Wald test for the null hypothesis that the importance $R_{t}^{v}$ is equal for all years.

\begin{tabular}{rccc} 
& \multicolumn{3}{c}{$\boldsymbol{H}_{\mathbf{0}}$ : Equality for all years } \\
\hline & $\mathrm{S} \& \mathrm{P}$ & Moody's & Fitch \\
\hline Eurozone membership & $\mathbf{0 . 0 0 0}$ & $\mathbf{0 . 0 0 0}$ & $\mathbf{0 . 0 0 6}$ \\
Financial balance & $\mathbf{0 . 0 0 1}$ & $\mathbf{0 . 0 0 0}$ & 0.079 \\
Economic development & 0.182 & $\mathbf{0 . 0 0 1}$ & $\mathbf{0 . 0 3 8}$ \\
External debt & $\mathbf{0 . 0 0 0}$ & $\mathbf{0 . 0 0 0}$ & $\mathbf{0 . 0 0 4}$ \\
GDP growth $\times$ Gov. debt & $\mathbf{0 . 0 0 0}$ & $\mathbf{0 . 0 1 8}$ & $\mathbf{0 . 0 1 8}$ \\
GDP growth & $\mathbf{0 . 0 0 5}$ & $\mathbf{0 . 0 1 4}$ & $\mathbf{0 . 0 3 6}$ \\
Government debt & $\mathbf{0 . 0 3 5}$ & $\mathbf{0 . 0 2 1}$ & $\mathbf{0 . 0 3 8}$ \\
Current account & 0.120 & 0.059 & 0.091 \\
Inflation & $\mathbf{0 . 0 0 0}$ & 0.274 & $\mathbf{0 . 0 0 0}$ \\
Default history & 0.132 & $\mathbf{0 . 0 3 5}$ & $\mathbf{0 . 0 0 4}$ \\
\hline
\end{tabular}

Second, we test, for each variable $v$ in $2, \ldots, p$, the hypothesis that the average importance is equal before and after 2009, which is the start of the European debt crisis

$$
H_{0}: \frac{1}{7} \sum_{t=2002}^{2008} R_{t}^{v}=\frac{1}{7} \sum_{t=2009}^{2015} R_{t}^{v} .
$$

The right panel of Table 4 shows the P-values of the Wald test for this null hypothesis. For most CRAs, the hypothesis of no break in 2009 is strongly rejected for eurozone membership, the financial balance, the economic development, the external debt, GDP growth and the interaction effect between GDP growth and government debt. Therefore, the previously discussed changes in the importance of these variables after 2009 are also statistically significant.

\subsection{Discussion}

In sum, for S\&P, Moody's and Fitch, we find that the importance of the financial balance, the economic development and the external debt increased substantially in magnitude after 2009 and that the effect of eurozone membership switched from positive to negative. In addition, GDP growth and government debt, as well as their interaction, gained much importance, such that the positive effect of GDP growth on the credit rating became considerable, especially for highly indebted sovereigns, and that the negative effect of government debt became large, especially for low growth countries. These empirical findings indicate a change in the sovereign credit rating assessment of CRAs after the start of the European debt crisis. There are several possible explanations for this change. 
A first explanation is that credit rating agencies had badly judged the importance of the different credit rating determinants with respect to default risk before 2009 and that they have permanently adjusted their rating methodology after the European debt crisis experience. Kiff et al. (2010) provide a similar argument for the change of importance of short term debt after the Asian crisis.

A second explanation could be that this change only holds temporary for the duration of the European sovereign debt crisis. This interpretation would be in line with Fitch (2014), who states that during crisis periods, a higher weight is attached to sovereign's finance ratios (as government debt and financial balance ratios) and financing flexibility. This larger weight of the sovereign's financing flexibility is reflected in the negative effect of eurozone membership after 2009, since eurozone member countries cannot force the central bank to provide them with sufficient liquidity.

\subsection{Model fit}

We compare the model fit of our multi-year ordered probit model to that of the single-year ordered probit model, the pooled ordered probit model with and without a structural break in 2009, the multiyear seemingly unrelated linear regression (SUR) model and the single year OLS linear regression model. $^{8}$ Table 6 shows the mean absolute error (MAE) ${ }^{9}$ and, in line with Afonso et al. (2007), the percentage of prediction errors that are within $x$ notches, with $x$ between 0 and 6 . The multi-year and single-year ordered probit models perform well. They have on the whole the lowest MAE (about 1.5) and the highest proportion of correctly predicted ratings within 0 and 1 notches (about $30 \%$ and $55 \%$ ). We also considered the logit specifications of the single-year and pooled ordered response models, leading to a slightly better model fit (results are available upon request).

Table 7 presents the frequency of upgrades and downgrades of the actual and fitted ratings, together with the percentage of actual upgrades and downgrades for which the timing is correctly predicted, i.e. the percentage of actual upgrades (downgrades) for which the sign of the change of the actual and fitted ratings coincide (similar as in Afonso et al., 2007). The multi-year ordered probit model performs very well: averaged over the three CRAs, it correctly predicts $44 \%$ of the rating

\footnotetext{
${ }^{8}$ For the OLS and SUR linear regression models, we have transformed the 21 credit rating categories of Table A.1 to an equally spaced linear scale ranging between 1 and 21, in line with Bissoondoyal-Bheenick et al. (2006) and Giacomino (2013). In line with Afonso et al. (2007), we round the fitted value of the OLS and SUR model to the nearest integer between 1 and 21. We compute the fitted value of the multi-year, single-year and pooled ordered probit models $\hat{Y}_{i t}$, as the rating category $l$ for which $\hat{\tau}_{t}^{l-1} \leq \hat{\beta}_{t}^{\prime} x_{i t}<\hat{\tau}_{t}^{l}$. The pooled ordered probit model with structural break is obtained by separately estimating a pooled ordered probit model for the subsamples 2002-2008 and 2009-2015.

${ }^{9}$ For the calculation of the mean absolute error, we consider the distance between subsequent rating categories to be one, in line with the linear scale used for the OLS and SUR linear regression models.
} 
Table 6: Mean absolute error (MAE) and the percentage of ratings for which the fitted value lies within $x$ notches, with $x$ between 0 and 6 .

\begin{tabular}{|c|c|c|c|c|c|c|c|c|c|}
\hline & & \multirow[t]{2}{*}{ MAE } & \multicolumn{7}{|c|}{$\%$ correctly predicted within $x$ notches } \\
\hline & & & $x=0$ & $x=1$ & $x=2$ & $x=3$ & $x=4$ & $x=5$ & $x=6$ \\
\hline \multirow{6}{*}{$\begin{array}{l}D_{1} \\
2 \\
\tilde{\Omega}\end{array}$} & Multi-year ordered probit & 1.57 & 0.28 & 0.56 & 0.77 & 0.89 & 0.96 & 0.99 & 0.99 \\
\hline & Single-year ordered probit & 1.51 & 0.31 & 0.58 & 0.78 & 0.90 & 0.95 & 0.98 & 0.99 \\
\hline & Pooled ordered probit & 1.72 & 0.26 & 0.54 & 0.74 & 0.86 & 0.94 & 0.97 & 0.99 \\
\hline & Structural break pooled probit & 1.63 & 0.27 & 0.56 & 0.75 & 0.88 & 0.95 & 0.98 & 0.99 \\
\hline & SUR linear regression & 1.79 & 0.18 & 0.49 & 0.74 & 0.88 & 0.96 & 0.98 & 0.99 \\
\hline & OLS linear regression & 1.60 & 0.22 & 0.55 & 0.79 & 0.90 & 0.96 & 0.99 & 0.99 \\
\hline \multirow{6}{*}{$\begin{array}{l}n \\
\dot{z} \\
\dot{0} \\
\dot{0} \\
\dot{z}\end{array}$} & Multi-year ordered probit & 1.59 & 0.30 & 0.55 & 0.77 & 0.88 & 0.95 & 0.98 & 0.99 \\
\hline & Single-year ordered probit & 1.53 & 0.33 & 0.57 & 0.78 & 0.89 & 0.95 & 0.97 & 0.99 \\
\hline & Pooled ordered probit & 1.81 & 0.26 & 0.50 & 0.72 & 0.85 & 0.93 & 0.96 & 0.98 \\
\hline & Structural break pooled probit & 1.71 & 0.28 & 0.51 & 0.75 & 0.86 & 0.94 & 0.97 & 0.99 \\
\hline & SUR linear regression & 1.88 & 0.17 & 0.48 & 0.71 & 0.86 & 0.94 & 0.97 & 0.99 \\
\hline & OLS linear regression & 1.62 & 0.22 & 0.56 & 0.77 & 0.90 & 0.96 & 0.98 & 1.00 \\
\hline \multirow{6}{*}{ 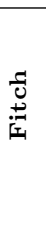 } & Multi-year ordered probit & 1.28 & 0.39 & 0.67 & 0.84 & 0.93 & 0.96 & 0.98 & 0.99 \\
\hline & Single-year ordered probit & 1.24 & 0.39 & 0.67 & 0.87 & 0.94 & 0.96 & 0.98 & 0.99 \\
\hline & Pooled ordered probit & 1.52 & 0.31 & 0.61 & 0.80 & 0.90 & 0.94 & 0.97 & 0.98 \\
\hline & Structural break pooled probit & 1.40 & 0.33 & 0.63 & 0.83 & 0.92 & 0.96 & 0.98 & 0.98 \\
\hline & SUR linear regression & 1.55 & 0.25 & 0.57 & 0.81 & 0.92 & 0.97 & 0.98 & 0.99 \\
\hline & OLS linear regression & 1.37 & 0.25 & 0.64 & 0.86 & 0.95 & 0.98 & 0.98 & 0.99 \\
\hline
\end{tabular}

Table 7: The frequency of upgrades and downgrades of the actual rating ('Actual') and the fitted rating ('Fitted') and the percentage of actual upgrades and downgrades for which the timing is correctly predicted ('\% Correct').

\begin{tabular}{|c|c|c|c|c|c|c|c|}
\hline & & \multicolumn{3}{|c|}{ Upgrades } & \multicolumn{3}{|c|}{ Downgrades } \\
\hline & & Actual & Fitted & $\%$ Correct & Actual & Fitted & $\%$ Correct \\
\hline \multirow{6}{*}{$\begin{array}{l}0 \\
\infty \\
\infty \\
\text { D. }\end{array}$} & Multi-year ordered probit & 0.16 & 0.22 & 0.45 & 0.11 & 0.18 & 0.49 \\
\hline & Single-year ordered probit & 0.16 & 0.27 & 0.45 & 0.11 & 0.23 & 0.45 \\
\hline & Pooled ordered probit & 0.16 & 0.19 & 0.29 & 0.11 & 0.13 & 0.32 \\
\hline & Structural break pooled probit & 0.16 & 0.21 & 0.30 & 0.11 & 0.18 & 0.39 \\
\hline & SUR linear regression & 0.16 & 0.19 & 0.34 & 0.11 & 0.16 & 0.46 \\
\hline & OLS linear regression & 0.16 & 0.27 & 0.40 & 0.11 & 0.23 & 0.45 \\
\hline \multirow{6}{*}{ 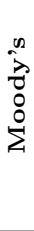 } & Multi-year ordered probit & 0.13 & 0.21 & 0.39 & 0.09 & 0.19 & 0.62 \\
\hline & Single-year ordered probit & 0.13 & 0.28 & 0.44 & 0.09 & 0.24 & 0.52 \\
\hline & Pooled ordered probit & 0.13 & 0.21 & 0.33 & 0.09 & 0.16 & 0.44 \\
\hline & Structural break pooled probit & 0.13 & 0.21 & 0.32 & 0.09 & 0.19 & 0.42 \\
\hline & SUR linear regression & 0.13 & 0.17 & 0.42 & 0.09 & 0.16 & 0.59 \\
\hline & OLS linear regression & 0.13 & 0.27 & 0.44 & 0.09 & 0.24 & 0.53 \\
\hline \multirow{6}{*}{ 苞 } & Multi-year ordered probit & 0.14 & 0.21 & 0.46 & 0.09 & 0.16 & 0.57 \\
\hline & Single-year ordered probit & 0.14 & 0.25 & 0.41 & 0.09 & 0.22 & 0.59 \\
\hline & Pooled ordered probit & 0.14 & 0.21 & 0.30 & 0.09 & 0.13 & 0.44 \\
\hline & Structural break pooled probit & 0.14 & 0.22 & 0.34 & 0.09 & 0.15 & 0.37 \\
\hline & SUR linear regression & 0.14 & 0.17 & 0.40 & 0.09 & 0.15 & 0.59 \\
\hline & OLS linear regression & 0.14 & 0.28 & 0.40 & 0.09 & 0.26 & 0.61 \\
\hline
\end{tabular}


upgrades and $56 \%$ of the rating downgrades, which is high given the rather infrequent occurrence of actual (and fitted) up- and downgrades. Finally, note that, for all models, rating changes occur more often for the fitted ratings (on average $22 \%$ for upgrades and $19 \%$ for downgrades) compared to actual ratings (on average 14\% for upgrades and $10 \%$ for downgrades), in line with the findings of $\mathrm{Hu}$ et al. (2002). This lower number of actual rating changes can be explained by a trade-off in the CRAs' rating system between stability and accuracy (Cantor and Mann, 2007; Gaillard, 2012).

\section{Conclusion}

This paper compares the importance of ten determinants of sovereign credit ratings over time for the three main credit rating agencies, using a sample of 90 countries for the years 2002-2015. Applying a composite marginal likelihood estimation approach, we estimate a multi-year ordered probit model.

We provide empirical evidence that the credit rating agencies changed their sovereign credit rating assessment after the start of the European debt crisis in 2009. The financial balance, the economic development and the external debt became substantially more important after 2009, and the effect of eurozone membership switched from positive to negative. In addition, GDP growth and government debt, as well as their interaction, gained much importance, such that the positive effect of GDP growth on the credit rating became considerable, especially for highly indebted sovereigns, and that the negative effect of government debt became large, especially for low growth countries. Very recent research corroborates several of our findings. Comparing estimated single-year linear regression coefficients between the years 2007 and 2015, Amstad and Packer (2015) find that the government debt to GDP ratio, the GDP growth rate and the flexibility of the exchange rate regime was more important for the latter year. Also Boumparis et al. (2015) and Giacomino (2013) detect that government debt became more important after 2008, using a panel linear regression model.

We compared the outcomes with several other models: the single-year probit and logit model and the pooled probit and logit model with a structural break in 2009. Note, however, that these benchmark models do not take into account the serial correlation of the error terms of the credit ratings and are therefore misspecified. We find that the estimated importance of most variables, as well as the results of the hypothesis test for their change after 2009, are very similar to those reported in the manuscript (results are available upon request). In particular, the increased importance after 2009 of the financial balance, the economic development, the external debt and the interaction between GDP growth and government debt, together with the switch of the effect of eurozone membership from strongly positive to highly negative, are confirmed. In addition, the change of 
importance of the interaction term is now statistically significant for all rating agencies and, for the pooled probit models with structural break, the decreased importance of inflation is statistically significant.

Several robustness analyses confirm our findings. We estimated the model both for the income level subsample of developing countries (countries that have a zero value in 2015 for the economic development dummy variable defined in Table 2) and for a regional subsample of non-eurozone countries in 2015. We find that the values of the estimated importance of the variables as well as their change after 2009 are very similar to those in the manuscript (results are available upon request). Only the change of the external debt for the income level subsample and the changes of the GDP growth rate and the interaction term for the regional subsample were not statistically significant, which could be explained by the reduced statistical power of these smaller samples.

We believe that our empirical model with ten determinants provides a good understanding of the credit rating process: the fitted ratings have an average absolute error of about 1.5 notches, about $55 \%$ lies within one notch of the actual rating and they could correctly predict the timing of about $50 \%$ of the actual rating up- and downgrades. Still, we acknowledge that our model remains a simplified representation of the complex sovereign credit rating process of the CRAs, which incorporates hundreds of variables as well as subjective judgment, and which can vary the relevance of the different determinants across countries (S\&P, 2008). Another limitation is that several of the variables that are used to model end-of-year sovereign credit ratings are not instantaneously available to the rating agencies, because they are published and revised several months after the end of the year. However, note that rating agencies do have access to other data series such as surveys, which could inform on the current values of these variables.

Our approach of analyzing the ratio of each coefficient relative to the coefficient of GDP per capita as a measure of importance of each variable, has the limitation that a change in this ratio does not inform per se on whether the weight of the numerator variable has changed or whether the weight of the denominator variable GDP per capita has changed. However, both a seemingly unrelated linear regression analysis and the linear regression model of Amstad and Packer (2015) indicate that the weight of GDP per capita was relatively constant over time (ignoring the bias that results from applying such linear regression models). This strengthens our interpretation that changes in the ratio correspond to changes in the weight of the numerator variable.

Finally, our model does not include possible interaction between the rating agencies, while one might argue that rating agencies are competitors and so react to each other rating decisions. Table A.2 of Appendix A shows the cross-correlations at different lags between the year-on-year change 
of the end-of-year ratings of the different rating agencies. While we find that rating agencies often change their ratings in the same year (the contemporaneous correlation between year-on-year rating changes is about 0.65), we do not find evidence for substantial lagged feedback effects across rating agencies (the cross-correlation of the rating changes at the one to three year lags are less than 0.11).

Our results provide insight in the sovereign credit rating process that are relevant to credit rating agencies, financial investors and governments. The model can be used by credit rating agencies as an

empirical approximation for their credit rating process. Furthermore, predictions of the credit rating for non-rated countries can be obtained. Finally, our quantification of the determinants of sovereign credit ratings can help governments to better understand the drivers of their credit rating.

\section{Acknowledgments}

We are thankful to the Editor and two anonymous referees for their helpful comments and suggestions. Furthermore, we thank Ferre De Graeve, Geert Dhaene, Gerdie Everaert, Michele Lenza and Frank Smets for comments on an earlier version of the manuscript. We are grateful to Peter Chovanec and Wouter Simons for their research assistance in the data collection. Finally, financial support from the Agency for Innovation by Science and Technology (IWT) in Flanders is kindly acknowledged.

\section{References}

Afonso, A., Gomes, P., and Rother, P. (2007). What 'hides' behind sovereign debt ratings? Working Paper 711, European Central Bank.

Afonso, A., Gomes, P., and Rother, P. (2009). Ordered response models for sovereign debt ratings. Applied Economics Letters, 16(8), 769-773.

Afonso, A., Gomes, P., and Rother, P. (2011). Short and long run determinants of sovereign debt credit ratings. International Journal of Finance \&3 Economics, 16(1), 1-15.

Allison, P. D. (1999). Comparing logit and probit coefficients across groups. Sociological Methods $\&$ Research, 28(2), 186-208.

Amstad, M. and Packer, F. (2015). Sovereign ratings of advanced and emerging economies after the crisis. BIS Quarterly review, pages 77-91. 
Beers, D. T. and Nadeau, J.-S. (2015). Database of sovereign defaults. Technical Report 101, Bank of Canada.

Bhat, C., Varin, C., and Ferdous, N. (2010). A comparison of the maximum simulated likelihood and composite marginal likelihood estimation approaches in the context of the multivariate ordered response model. In W. Greene and R. Hill, editors, Advances in Econometrics: Maximum Simulated Likelihood Methods and Applications, volume 26, pages 65-106. Emerald Group Publishing Limited.

Bissoondoyal-Bheenick, E. (2005). An analysis of the determinants of sovereign ratings. Global Finance Journal, 15(3), 251-280.

Bissoondoyal-Bheenick, E., Brooks, R., and Yip, A. Y. (2006). Determinants of sovereign ratings: A comparison of case-based reasoning and ordered probit approaches. Global Finance Journal, 17(1), $136-154$.

Boes, S. and Winkelmann, R. (2006). The effect of income on positive and negative subjective well-being. SOI - Working Papers 0605, Socioeconomic Institute - University of Zurich.

Boumparis, P., Milas, C., and Panagiotidis, T. (2015). Has the crisis affected the behavior of the rating agencies? Panel evidence from the eurozone. Economics Letters, 136(C), 118-124.

Cantor, R. and Mann, C. (2007). Analyzing the tradeoff between ratings accuracy and stability. Journal of Fixed Income, pages 60-68.

Cantor, R. and Packer, F. (1996). Determinants and impact of sovereign credit ratings. Economic Policy Review, pages 37-53.

Christensen, R. H. B. (2015). Analysis of ordinal data with cumulative link models. Estimation with the $\mathrm{R}$ package Ordinal.

De Grauwe, P. and Ji, Y. (2013). Self-fulfilling crises in the eurozone: An empirical test. Journal of International Money and Finance, 34, 15 - 36.

Elkhoury, M. (2007). Credit rating agencies and their potential impact on developing countries. UNCTAD Discussion Papers 186, United Nations Conference on Trade and Development.

Ferdous, N., Eluru, N., Bhat, C. R., and Meloni, I. (2010). A multivariate ordered-response model system for adults' weekday activity episode generation by activity purpose and social context. Transportation Research Part B: Methodological, 44(8-9), 922-943. 
Fitch (2014). Sovereign rating criteria. Technical report.

Gaillard, N. (2012). A century of sovereign ratings. Springer-Verlag New York.

Gartner, M., Griesbach, B., and Jung, F. (2011). PIGS or lambs? the European sovereign debt crisis and the role of rating agencies. International Advances in Economic Research, 17(3), 288-299.

Genz, A. (1992). Numerical computation of multivariate normal probabilities. Journal of Computational and Graphical Statistics, 1(2), 141-149.

Giacomino, P. (2013). Are sovereign credit ratings pro-cyclical? a controversial issue revisited in light of the current financial crisis. Rivista di Politica Economica, (4), 79-111.

Greene, W. and Hensher, D. (2010). Modeling ordered choices: a primer. Cambridge University Press, New York.

Hill, P., Brooks, R., and Faff, R. (2010). Variations in sovereign credit quality assessments across rating agencies. Journal of Banking $\&$ Finance, 34(6), 1327-1343.

Hoetker, G. (2004). Confounded coefficients: Extending recent advances in the accurate comparison of logit and probit coefficients across groups. Working paper.

Hoetker, G. (2007). The use of logit and probit models in strategic management research: Critical issues. Strategic Management Journal, 28(4), 331-343.

Hu, Y.-T., Kiesel, R., and Perraudin, W. (2002). The estimation of transition matrices for sovereign credit ratings. Journal of Banking \& Finance, 26(7), 1383-1406.

Kiff, J., Holland, A., Kisser, M., Nowak, S., Saab, S., Schumacher, L., van der Hoorn, H., and Westin, A.-M. (2010). The uses and abuses of sovereign credit ratings. In Global Financial Stability Report, volume 10/2010. International Monetary Fund.

McKelvey, R. D. and Zavoina, W. (1975). A statistical model for the analysis of ordinal level dependent variables. The Journal of Mathematical Sociology, 4(1), 103-120.

Monfort, B. and Mulder, C. (2000). Using credit ratings for capital requirements on lending to emerging market economies - possible impact of a new Basel accord. Technical Report 00/69, IMF Working Papers.

Moody's (2015a). Moody's statistical handbook country credit. Technical report, Moody's Investor Service. 
Moody's (2015b). Sovereign bond ratings. Technical report, Moody's Investor Service.

Mora, N. (2006). Sovereign credit ratings: guilty beyond reasonable doubt? Journal of Banking \& Finance, 30(7), 2041-2062.

S\&P (2008). Sovereign credit ratings: A primer. Technical report, Standard and Poor's.

S\&P (2014a). How S\&P factors in monetary union membership in its sovereign ratings. Technical report, Standard and Poor's.

S\&P (2014b). Sovereign rating methodology. Technical report, Standard and Poor's.

Train, K. (1998). Recreation demand models with taste differences over people. Land economics, 74(2), 230-239.

Train, K. (2003). Discrete choice methods with simulation. Cambridge University Press.

Varin, C. and Czado, C. (2010). A mixed autoregressive probit model for ordinal longitudinal data. Biostatistics, 11(1), 127-138.

Varin, C., Reid, N., and Firth, D. (2011). An overview of composite likelihood methods. Statistica Sinica, 21(1), 5-42.

Zhao, Y. and Joe, H. (2005). Composite likelihood estimation in multivariate data analysis. The Canadian Journal of Statistics, 33(3), 335-356. 


\section{Appendix A. Data Appendix}

Table A.1: The sovereign credit rating categories used by S\&P, Moody's and Fitch.

\begin{tabular}{cccc} 
Category number & S\&P & Moody's & Fitch \\
\hline 21 & $\mathrm{AAA}$ & $\mathrm{Aaa}$ & $\mathrm{AAA}$ \\
20 & $\mathrm{AA}+$ & $\mathrm{Aa} 1$ & $\mathrm{AA}+$ \\
19 & $\mathrm{AA}$ & $\mathrm{Aa} 2$ & $\mathrm{AA}$ \\
18 & $\mathrm{AA}-$ & $\mathrm{Aa} 3$ & $\mathrm{AA}-$ \\
17 & $\mathrm{~A}+$ & $\mathrm{A} 1$ & $\mathrm{~A}+$ \\
16 & $\mathrm{~A}$ & $\mathrm{~A} 2$ & $\mathrm{~A}$ \\
15 & $\mathrm{~A}-$ & $\mathrm{A} 3$ & $\mathrm{~A}-$ \\
14 & $\mathrm{BBB}+$ & $\mathrm{Baa} 1$ & $\mathrm{BBB}+$ \\
13 & $\mathrm{BBB}$ & $\mathrm{Baa} 2$ & $\mathrm{BBB}$ \\
12 & $\mathrm{BBB}-$ & $\mathrm{Baa} 3$ & $\mathrm{BBB}-$ \\
11 & $\mathrm{BB}+$ & $\mathrm{Ba} 1$ & $\mathrm{BB}+$ \\
10 & $\mathrm{BB}$ & $\mathrm{Ba} 2$ & $\mathrm{BB}$ \\
9 & $\mathrm{BB}-$ & $\mathrm{Ba} 3$ & $\mathrm{BB}-$ \\
8 & $\mathrm{~B}+$ & $\mathrm{B} 1$ & $\mathrm{~B}+$ \\
7 & $\mathrm{~B}$ & $\mathrm{~B} 2$ & $\mathrm{~B}$ \\
6 & $\mathrm{~B}-$ & $\mathrm{B} 3$ & $\mathrm{~B}-$ \\
5 & $\mathrm{CCC}+$ & $\mathrm{Caa} 1$ & $\mathrm{CCC}+$ \\
4 & $\mathrm{CCC}$ & $\mathrm{Caa} 2$ & $\mathrm{CCC}$ \\
3 & $\mathrm{CCC}-$ & $\mathrm{Caa} 3$ & $\mathrm{CCC}-$ \\
2 & $\mathrm{CC}$ & $\mathrm{Ca}$ & $\mathrm{CC} / \mathrm{C}$ \\
1 & $\mathrm{SD} / \mathrm{D}$ & $\mathrm{C}$ & $\mathrm{D} / \mathrm{RD}$
\end{tabular}

Table A.2: The cross-correlations at different lags $h$ between the year-on-year change of the end-of-year ratings of the different rating agencies.

\begin{tabular}{r|rrrrrrr}
\hline $\mathrm{h}$ & -3 & -2 & -1 & 0 & 1 & 2 & 3 \\
\hline $\mathrm{S} \& \mathrm{P}(\mathrm{t}+\mathrm{h})$, Moody's(t) & -0.02 & 0.04 & 0.04 & 0.64 & 0.07 & 0.09 & 0.01 \\
$\mathrm{~S} \& \mathrm{P}(\mathrm{t}+\mathrm{h})$, Fitch(t) & 0.03 & 0.02 & 0.05 & 0.68 & 0.06 & 0.11 & 0.02 \\
Moody's(t+h),Fitch(t) & 0.03 & 0.06 & 0.06 & 0.63 & 0.05 & 0.05 & 0.00
\end{tabular}


Table A.3: The countries included in the sample for S\&P, Moody's and Fitch, denoted by ' $\mathrm{x}$ '.

\begin{tabular}{|c|c|c|c|}
\hline & $\mathrm{S} \& \mathrm{P}$ & Moody's & Fitch \\
\hline Argentina & $\mathrm{x}$ & $\mathrm{x}$ & $\mathrm{x}$ \\
\hline Australia & $\mathrm{x}$ & $\mathrm{x}$ & $\mathrm{x}$ \\
\hline Austria & $\mathrm{x}$ & $\mathrm{x}$ & $\mathrm{x}$ \\
\hline Bahamas, The & & $x$ & \\
\hline Bahrain & $\mathrm{x}$ & $\mathrm{x}$ & $\mathrm{x}$ \\
\hline Barbados & $\mathrm{x}$ & $\mathrm{x}$ & \\
\hline Belgium & $\mathrm{x}$ & $\mathrm{x}$ & $\mathrm{x}$ \\
\hline Belize & $\mathrm{x}$ & $\mathrm{x}$ & \\
\hline Bolivia & $\mathrm{x}$ & $\mathrm{x}$ & \\
\hline Botswana & $\mathrm{x}$ & & \\
\hline Brazil & $\mathrm{x}$ & $\mathrm{x}$ & $\mathrm{x}$ \\
\hline Bulgaria & $\mathrm{x}$ & $\mathrm{x}$ & $\mathrm{x}$ \\
\hline Canada & $\mathrm{x}$ & $\mathrm{x}$ & $\mathrm{x}$ \\
\hline Chile & $\mathrm{x}$ & $\mathrm{x}$ & $\mathrm{x}$ \\
\hline China & $\mathrm{x}$ & $\mathrm{x}$ & $\mathrm{x}$ \\
\hline Colombia & $\mathrm{x}$ & $\mathrm{x}$ & $\mathrm{x}$ \\
\hline Costa Rica & $\mathrm{x}$ & $\mathrm{x}$ & $\mathrm{x}$ \\
\hline Croatia & $\mathrm{x}$ & $\mathrm{x}$ & $\mathrm{x}$ \\
\hline Cyprus & $\mathrm{x}$ & $\mathrm{x}$ & $\mathrm{x}$ \\
\hline Czech Republic & $\mathrm{x}$ & $x$ & $\mathrm{x}$ \\
\hline Denmark & $\mathrm{x}$ & $\mathrm{x}$ & $\mathrm{x}$ \\
\hline Dominican Republic & $\mathrm{x}$ & $\mathrm{x}$ & \\
\hline Ecuador & $\mathrm{x}$ & $\mathrm{x}$ & $\mathrm{x}$ \\
\hline Egypt, Arab Rep. & $\mathrm{x}$ & $\mathrm{x}$ & $\mathrm{x}$ \\
\hline El Salvador & $\mathrm{x}$ & $\mathrm{x}$ & $\mathrm{x}$ \\
\hline Estonia & $\mathrm{x}$ & $\mathrm{x}$ & $\mathrm{x}$ \\
\hline Fiji & & $\mathrm{x}$ & \\
\hline Finland & $\mathrm{x}$ & $\mathrm{x}$ & $\mathrm{x}$ \\
\hline France & $\mathrm{x}$ & $\mathrm{x}$ & $\mathrm{x}$ \\
\hline Germany & $\mathrm{x}$ & $\mathrm{x}$ & $\mathrm{x}$ \\
\hline Greece & $\mathrm{x}$ & $\mathrm{x}$ & $\mathrm{x}$ \\
\hline Guatemala & $\mathrm{x}$ & $\mathrm{x}$ & \\
\hline Honduras & & $\mathrm{x}$ & \\
\hline Hong Kong SAR, China & $\mathrm{x}$ & $\mathrm{x}$ & $\mathrm{x}$ \\
\hline Hungary & $\mathrm{x}$ & $\mathrm{x}$ & $\mathrm{x}$ \\
\hline Iceland & $\mathrm{x}$ & $\mathrm{x}$ & $\mathrm{x}$ \\
\hline India & $\mathrm{x}$ & $\mathrm{x}$ & $\mathrm{x}$ \\
\hline Indonesia & $\mathrm{x}$ & $\mathrm{x}$ & $\mathrm{x}$ \\
\hline Ireland & $\mathrm{x}$ & $\mathrm{x}$ & $\mathrm{x}$ \\
\hline Israel & $\mathrm{x}$ & $\mathrm{x}$ & $\mathrm{x}$ \\
\hline Italy & $\mathrm{x}$ & $\mathrm{x}$ & $\mathrm{x}$ \\
\hline Jamaica & $\mathrm{x}$ & $\mathrm{x}$ & \\
\hline Japan & $\mathrm{x}$ & $\mathrm{x}$ & $\mathrm{x}$ \\
\hline Jordan & $\mathrm{x}$ & $\mathrm{x}$ & \\
\hline Kazakhstan & $\mathrm{x}$ & $\mathrm{x}$ & $\mathrm{x}$ \\
\hline Korea, Rep. & $\mathrm{x}$ & $x$ & $x$ \\
\hline Kuwait & $\mathrm{x}$ & $\mathrm{x}$ & $\mathrm{x}$ \\
\hline
\end{tabular}

\begin{tabular}{|c|c|c|c|}
\hline & $\mathrm{S} \& \mathrm{P}$ & Moody's & Fitch \\
\hline Latvia & $\mathrm{x}$ & $\mathrm{x}$ & $\mathrm{x}$ \\
\hline Lebanon & $\mathrm{x}$ & $\mathrm{x}$ & $\mathrm{x}$ \\
\hline Lithuania & $\mathrm{x}$ & $\mathrm{x}$ & $\mathrm{x}$ \\
\hline Luxembourg & $\mathrm{x}$ & $\mathrm{x}$ & $\mathrm{x}$ \\
\hline Malta & $\mathrm{x}$ & $\mathrm{x}$ & $\mathrm{x}$ \\
\hline Mauritius & & $\mathrm{x}$ & \\
\hline Mexico & $\mathrm{x}$ & $\mathrm{x}$ & $\mathrm{x}$ \\
\hline Morocco & $\mathrm{x}$ & $\mathrm{x}$ & \\
\hline Netherlands & $\mathrm{x}$ & $\mathrm{x}$ & $\mathrm{x}$ \\
\hline New Zealand & $\mathrm{x}$ & $\mathrm{x}$ & $\mathrm{x}$ \\
\hline Nicaragua & & $\mathrm{x}$ & \\
\hline Norway & $\mathrm{x}$ & $\mathrm{x}$ & $\mathrm{x}$ \\
\hline Oman & $\mathrm{x}$ & $\mathrm{x}$ & \\
\hline Pakistan & $\mathrm{x}$ & $\mathrm{x}$ & \\
\hline Panama & $\mathrm{x}$ & $\mathrm{x}$ & $\mathrm{x}$ \\
\hline Papua New Guinea & $\mathrm{x}$ & $\mathrm{x}$ & \\
\hline Paraguay & $\mathrm{x}$ & $\mathrm{x}$ & \\
\hline Peru & $\mathrm{x}$ & $\mathrm{x}$ & $\mathrm{x}$ \\
\hline Philippines & $\mathrm{x}$ & $\mathrm{x}$ & $\mathrm{x}$ \\
\hline Poland & $\mathrm{x}$ & $\mathrm{x}$ & $\mathrm{x}$ \\
\hline Portugal & $\mathrm{x}$ & $\mathrm{x}$ & $\mathrm{x}$ \\
\hline Qatar & $\mathrm{x}$ & $\mathrm{x}$ & \\
\hline Romania & $\mathrm{x}$ & $\mathrm{x}$ & $\mathrm{x}$ \\
\hline Russian Federation & $x$ & $\mathrm{x}$ & $\mathrm{x}$ \\
\hline Saudi Arabia & & $\mathrm{x}$ & \\
\hline Senegal & $\mathrm{x}$ & & \\
\hline Singapore & $\mathrm{x}$ & $\mathrm{x}$ & $\mathrm{x}$ \\
\hline Slovak Republic & $\mathrm{x}$ & $\mathrm{x}$ & $\mathrm{x}$ \\
\hline Slovenia & $\mathrm{x}$ & $\mathrm{x}$ & $\mathrm{x}$ \\
\hline South Africa & $\mathrm{x}$ & $\mathrm{x}$ & $\mathrm{x}$ \\
\hline Spain & $\mathrm{x}$ & $\mathrm{x}$ & $\mathrm{x}$ \\
\hline Suriname & $\mathrm{x}$ & & \\
\hline Sweden & $\mathrm{x}$ & $\mathrm{x}$ & $\mathrm{x}$ \\
\hline Switzerland & $\mathrm{x}$ & $\mathrm{x}$ & $\mathrm{x}$ \\
\hline Taiwan & $\mathrm{x}$ & $\mathrm{x}$ & $\mathrm{x}$ \\
\hline Thailand & $\mathrm{x}$ & $\mathrm{x}$ & $\mathrm{x}$ \\
\hline Trinidad and Tobago & $\mathrm{x}$ & $\mathrm{x}$ & \\
\hline Tunisia & & $\mathrm{x}$ & $\mathrm{x}$ \\
\hline Turkey & $\mathrm{x}$ & $\mathrm{x}$ & $\mathrm{x}$ \\
\hline Ukraine & $\mathrm{x}$ & $\mathrm{x}$ & $\mathrm{x}$ \\
\hline United Arab Emirates & & $\mathrm{x}$ & \\
\hline United Kingdom & $\mathrm{x}$ & $\mathrm{x}$ & $\mathrm{x}$ \\
\hline United States & $\mathrm{x}$ & $\mathrm{x}$ & $\mathrm{x}$ \\
\hline Uruguay & $\mathrm{x}$ & $\mathrm{x}$ & $\mathrm{x}$ \\
\hline Venezuela, RB & $\mathrm{x}$ & $\mathrm{x}$ & $\mathrm{x}$ \\
\hline Vietnam & $\mathrm{x}$ & $x$ & $\mathrm{x}$ \\
\hline
\end{tabular}




\section{Appendix B. The composite likelihood estimator of the multi-year ordered probit model}

Appendix B.1. The composite likelihood function

The logarithm of the composite likelihood function $L^{C}(\theta)$, defined in (5), can be written as

$$
\log L^{C}(\theta)=\sum_{i=1}^{N} \sum_{s=1}^{T-1} \sum_{t=s+1}^{T} \sum_{j=1}^{C_{s}} \sum_{k=1}^{C_{t}} I\left[y_{i s}=j, y_{i t}=k\right] \times \log P\left(Y_{i s}=j, Y_{i t}=k\right),
$$

where $y_{i s}$ and $y_{i t}$ denote the observed category of variables $Y_{i s}$ and $Y_{i t} . P\left(Y_{i s}=j, Y_{i t}=k\right)$ is given by

$$
\begin{gathered}
P\left(Y_{i s}=j, Y_{i t}=k\right)=P\left(\tau_{i s}^{j-1}<\nu_{i s}<\tau_{i s}^{j}, \tau_{i t}^{k-1}<\nu_{i t}<\tau_{i t}^{k}\right) \\
=\Phi_{2}\left(\tau_{i s}^{j}, \tau_{i t}^{k} ; \Sigma_{s t}\right)+\Phi_{2}\left(\tau_{i s}^{j-1}, \tau_{i t}^{k-1} ; \Sigma_{s t}\right)-\Phi_{2}\left(\tau_{i s}^{j}, \tau_{i t}^{k-1} ; \Sigma_{s t}\right)-\Phi_{2}\left(\tau_{i s}^{j-1}, \tau_{i t}^{k} ; \Sigma_{s t}\right),
\end{gathered}
$$

where $\Phi_{2}(\cdot, \cdot ; \rho)$ is the cdf of the bivariate normal distribution function with correlation parameter $\rho$ and unit variances, and where $\tau_{i t}^{l}$ is defined as

$$
\tau_{i t}^{l}=\tau_{t}^{l}-\beta_{t} x_{i t}
$$

for $i$ in $1, \ldots, N, t$ in $1, \ldots, T$ and $l$ in $0, \ldots, C_{t}$.

Appendix B.2. The covariance matrix of the composite likelihood estimator

The covariance matrix of the composite likelihood estimator $\operatorname{Cov}(\hat{\theta})$ equals the inverse of the Godambe's sandwich information matrix $G(\theta)$ (Zhao and Joe, 2005)

$$
\operatorname{Cov}(\hat{\theta})=G(\theta)^{-1}=H(\theta)^{-1} J(\theta) H(\theta)^{-1},
$$

where

$$
\begin{gathered}
J(\theta)=E\left[\left(\frac{\partial \log L^{C}(\theta)}{\partial \theta}\right)\left(\frac{\partial \log L^{C}(\theta)}{\partial \theta}\right)^{\prime}\right] \\
H(\theta)=E\left[\frac{\partial^{2} \log L^{C}(\theta)}{\partial \theta \partial \theta^{\prime}}\right],
\end{gathered}
$$


where $\theta$ is the vector collecting all unknown elements, as defined in Section 3.1. The matrices $H(\theta)$ and $J(\theta)$ can be estimated as follows (Bhat et al., 2010; Ferdous et al., 2010; Varin et al., 2011)

$$
\begin{gathered}
\hat{J}(\hat{\theta})=\sum_{i=1}^{N}\left[\left(\frac{\partial \log L_{i}^{C}(\theta)}{\partial \theta}\right)\left(\frac{\partial \log L_{i}^{C}(\theta)}{\partial \theta}\right)^{\prime}\right]_{\hat{\theta}} \\
=\sum_{i=1}^{N}\left(\sum_{s=1}^{T-1} \sum_{t=s+1}^{T} \sum_{j=1}^{C_{s}} \sum_{k=1}^{C_{t}} \frac{I\left[y_{i s}=j, y_{i t}=k\right]}{P\left(Y_{i s}=j, Y_{i t}=k\right)} \frac{\partial P\left(Y_{i s}=j, Y_{i t}=k\right)}{\partial \theta}\right)_{\hat{\theta}} \\
\times\left(\sum_{s=1}^{T-1} \sum_{t=s+1}^{T} \sum_{j=1}^{C_{s}} \sum_{k=1}^{C_{t}} \frac{I\left[y_{i s}=j, y_{i t}=k\right]}{P\left(Y_{i s}=j, Y_{i t}=k\right)} \frac{\partial P\left(Y_{i s}=j, Y_{i t}=k\right)}{\partial \theta}\right)_{\hat{\theta}}
\end{gathered}
$$

and

$$
\begin{gathered}
\hat{H}(\hat{\theta})=\sum_{i=1}^{N}\left[\frac{\partial^{2} \log L_{i}^{C}(\theta)}{\partial \theta \partial \theta^{\prime}}\right]_{\hat{\theta}} \\
=\sum_{i=1}^{N} \sum_{s=1}^{T-1} \sum_{t=s+1}^{T} \sum_{j=1}^{C_{s}} \sum_{k=1}^{C_{t}} I\left[y_{i s}=j, y_{i t}=k\right]\left[\frac{\partial^{2} \log P\left(Y_{i s}=j, Y_{i t}=k\right)}{\partial \theta \partial \theta^{\prime}}\right]_{\hat{\theta}} \\
=-\sum_{i=1}^{N} \sum_{s=1}^{T-1} \sum_{t=s+1}^{T} \sum_{j=1}^{C_{s}} \sum_{k=1}^{C_{t}}\left[\frac{I\left[y_{i s}=j, y_{i t}=k\right]}{P\left(Y_{i s}=j, Y_{i t}=k\right)^{2}}\right. \\
\left.\frac{\partial P\left(Y_{i s}=j, Y_{i t}=k\right)}{\partial \theta} \frac{\partial P\left(Y_{i s}=j, Y_{i t}=k\right)^{\prime}}{\partial \theta}\right]_{\hat{\theta}}
\end{gathered}
$$

where $L_{i}^{C}$ is defined in (6) and the $\hat{\theta}$ subscript denotes that the function is evaluated at the composite likelihood estimator $\hat{\theta}$.

For $1 \leq i \leq N, 1 \leq s<t \leq T, j$ in $1, \ldots, C_{s}$ and $k$ in $1, \ldots, C_{t}$, the nonzero elements of the vector $\frac{\partial P\left(Y_{i s}=j, Y_{i t}=k\right)}{\partial \theta}$ used in (B.4) and (B.5) can be computed from (B.2) and are given below:

- the component corresponding to $\tau_{s}^{j-1}$ with $2 \leq j \leq C_{s}$ :

$$
\phi\left(\tau_{i s}^{j-1}\right)\left(\Phi\left(\frac{\tau_{i t}^{k-1}-\Sigma_{s t} \tau_{i s}^{j-1}}{\sqrt{1-\Sigma_{s t}^{2}}}\right)-\Phi\left(\frac{\tau_{i t}^{k}-\Sigma_{s t} \tau_{i s}^{j-1}}{\sqrt{1-\Sigma_{s t}^{2}}}\right)\right)
$$

- the component corresponding to $\tau_{s}^{j}$ with $1 \leq j \leq C_{s}-1$ :

$$
\phi\left(\tau_{i s}^{j}\right)\left(\Phi\left(\frac{\tau_{i t}^{k}-\Sigma_{s t} \tau_{i s}^{j}}{\sqrt{1-\Sigma_{s t}^{2}}}\right)-\Phi\left(\frac{\tau_{i t}^{k-1}-\Sigma_{s t} \tau_{i s}^{j}}{\sqrt{1-\Sigma_{s t}^{2}}}\right)\right)
$$

- the component corresponding to $\tau_{t}^{k-1}$ with $2 \leq k \leq C_{t}$ :

$$
\phi\left(\tau_{i t}^{k-1}\right)\left(\Phi\left(\frac{\tau_{i s}^{j-1}-\Sigma_{s t} \tau_{i t}^{k-1}}{\sqrt{1-\Sigma_{s t}^{2}}}\right)-\Phi\left(\frac{\tau_{i s}^{j}-\Sigma_{s t} \tau_{i t}^{k-1}}{\sqrt{1-\Sigma_{s t}^{2}}}\right)\right)
$$


- the component corresponding to $\tau_{t}^{k}$ with $1 \leq k \leq C_{t}-1$ :

$$
\phi\left(\tau_{i t}^{k}\right)\left(\Phi\left(\frac{\tau_{i s}^{j}-\Sigma_{s t} \tau_{i t}^{k}}{\sqrt{1-\Sigma_{s t}^{2}}}\right)-\Phi\left(\frac{\tau_{i s}^{j-1}-\Sigma_{s t} \tau_{i t}^{k}}{\sqrt{1-\Sigma_{s t}^{2}}}\right)\right)
$$

- the $p$ components corresponding to $\beta_{s}:{ }^{10}$

$$
\begin{gathered}
\left(-x_{i s}\right)\left\{\left(\phi\left(\tau_{i s}^{j}\right) \Phi\left(\frac{\tau_{i t}^{k}-\Sigma_{s t} \tau_{i s}^{j}}{\sqrt{1-\Sigma_{s t}^{2}}}\right)+\phi\left(\tau_{i s}^{j-1}\right) \Phi\left(\frac{\tau_{i t}^{k-1}-\Sigma_{s t} \tau_{i s}^{j-1}}{\sqrt{1-\Sigma_{s t}^{2}}}\right)\right.\right. \\
\left.-\phi\left(\tau_{i s}^{j}\right) \Phi\left(\frac{\tau_{i t}^{k-1}-\Sigma_{s t} \tau_{i s}^{j}}{\sqrt{1-\Sigma_{s t}^{2}}}\right)-\phi\left(\tau_{i s}^{j-1}\right) \Phi\left(\frac{\tau_{i t}^{k}-\Sigma_{s t} \tau_{i s}^{j-1}}{\sqrt{1-\Sigma_{s t}^{2}}}\right)\right\}
\end{gathered}
$$

- the $p$ components corresponding to $\beta_{t}$ :

$$
\begin{gathered}
\left(-x_{i t}\right)\left\{\phi\left(\tau_{i t}^{k}\right) \Phi\left(\frac{\tau_{i s}^{j}-\Sigma_{s t} \tau_{i t}^{k}}{\sqrt{1-\Sigma_{s t}^{2}}}\right)+\phi\left(\tau_{i t}^{k-1}\right) \Phi\left(\frac{\tau_{i s}^{j-1}-\Sigma_{s t} \tau_{i t}^{k-1}}{\sqrt{1-\Sigma_{s t}^{2}}}\right)\right. \\
\left.-\phi\left(\tau_{i t}^{k}\right) \Phi\left(\frac{\tau_{i s}^{j-1}-\Sigma_{s t} \tau_{i t}^{k}}{\sqrt{1-\Sigma_{s t}^{2}}}\right)-\phi\left(\tau_{i t}^{k-1}\right) \Phi\left(\frac{\tau_{i s}^{j}-\Sigma_{s t} \tau_{i t}^{k-1}}{\sqrt{1-\Sigma_{s t}^{2}}}\right)\right\}
\end{gathered}
$$

- the component corresponding to $\rho$ :

$$
\begin{gathered}
|t-s| \rho^{|t-s|-1} \\
\left(\phi_{2}\left(\tau_{i s}^{j}, \tau_{i t}^{k} ; \Sigma_{s t}\right)+\phi_{2}\left(\tau_{i s}^{j-1}, \tau_{i t}^{k-1} ; \Sigma_{s t}\right)-\phi_{2}\left(\tau_{i s}^{j}, \tau_{i t}^{k-1} ; \Sigma_{s t}\right)-\phi_{2}\left(\tau_{i s}^{j-1}, \tau_{i t}^{k} ; \Sigma_{s t}\right)\right)
\end{gathered}
$$

where $\Phi(\cdot)$ denotes the standard normal distribution function, $\phi(\cdot)$ denotes the standard normal density function and $\phi_{2}\left(\cdot, \cdot ; \Sigma_{s t}\right)$ denotes the bivariate normal density function with correlation parameter $\Sigma_{s t}$ and unit variances.

Appendix B.3. Implementation of the composite likelihood estimator

We perform two reparameterizations. First, we write the autoregressive parameter $\rho$, between -1 and 1 , as the hyperbolic tangent transformation of an unrestricted parameter $\rho_{\text {atanh }}$. Second, in line with Greene and Hensher (2010), we reparametrize the threshold coefficients $\tau_{t}^{l}$ to ensure that the ordering $\tau_{t}^{i}<\tau_{t}^{j}$ for $i<j$ is preserved. Define $\gamma_{t}^{j}$, for each $t$ in $1, \ldots, T$ as

$$
\begin{gathered}
\tau_{t}^{1}=\gamma_{t}^{1} \\
\tau_{t}^{j}=\tau_{t}^{j-1}+\exp \left(\gamma_{t}^{j}\right) \quad \text { for } j \text { in } 2, \ldots, C_{t}-1 .
\end{gathered}
$$

\footnotetext{
${ }^{10}$ In (B.10), we use the convention that the first component equals zero when both $j=C_{s}$ and $k=C_{t}$ and that the second component equals zero when both $j=1$ and $k=1$. A similar convention applies for (B.11).
} 
We maximize the composite likelihood using the BFGS algorithm implemented in the 'optim' function of the R package 'stats'. The gradient of the composite likelihood function, which is used in the BFGS optimization algorithm, is computed analytically from (B.1). The bivariate normal probabilities of the pairwise composite loglikelihood function in (B.1) are computed using the Genz (1992) algorithm implemented in the $\mathrm{R}$ package mnormt. The starting values for the parameters $\beta_{t}$ and $\gamma_{t}^{j}$ are chosen as the maximum likelihood estimates from the single-year ordered probit model. The starting values of the $\rho_{\text {atanh }}$ parameter is the inverse hyperbolic tangent transformation of the average of the estimates of the off-diagonal elements of the estimated covariance matrix of the seemingly unrelated linear regression model to the power $1 /|t-s|$, where $s$ and $t$ denote the row and column number. 